\title{
TROCA DE OPERADORES E EQUIPAMENTOS NA MENSURAÇÃO DAS VARIAVEIS DENDROMETRICAS DE ÁRVORES CLONAIS DE EUCALYPTUS
}

Plínio Carielo, Renato de Araújo Ferreira, João Luiz DalPonte Filho, Raimundo Nonato A. da Silva, Renan Gomes Ferreira, Izidio Marra Junior, Adilson Thadeu Pereira Lopes, Jean Nascimento Oliveira, Renan de Jesus Santos, Tassiane Sanchez, Fernando de Lima Ribeiro.

Escola Técnica Estadual Prof. Dr. Antonio Eufrásio de Toledo - ETEC, Técnico em Florestas, Presidente Prudente, SP. Email: pliniocarielo@hotmail.com

\section{RESUMO}

A mensuração correta das variáveis dendrométricas de uma árvore é essencial para garantir qualidade e confiabilidade dos resultados de um levantamento florestal. As variáveis dendrométricas mais importantes são o diâmetro a altura do peito (DAP) e a altura total. Todos os levantamentos são susceptíveis aos erros relacionados à precisão dos equipamentos e a falta de habilidade dos operadores. Visando avaliar estes erros este trabalho, comparou-se as medições realizadas por diferentes operadores e equipamentos para as variáveis DAP e altura total de um povoamento de Eucalyptus clonal localizado na ETEC Prof. Dr. Antonio Eufrásio de Toledo. Para avaliar a diferença entre os tratamentos utilizou-se o procedimento de análise de variância e teste de média Scott knott a 1 e 5\% de probabilidade. Os resultados encontrados mostram que não há diferença entre os tratamentos testados para a variável DAP e que há diferença para a variável altura total.

Palavras - chave: Mensuração, Comparação, Operadores, Equipamentos, Eucalyptus

\section{OPERATORS OF EXCHANGE AND EQUIPMENT IN THE MEASUREMENT OF VARIABLE DENDROMETRIC OF CLONAL EUCALYPTUS TREES.}

\begin{abstract}
ABSTRAT
The correct measurement of dendrometric variables of a tree is essential to ensure quality and reliability of the results of a forest survey. The most important variables are dendrometric the diameter at breast height (DAP) and height. All surveys are susceptible to errors related to the accuracy of the equipment and the inability of the operators. To evaluate these errors this study compared measurements made by different operators and equipment for the DAP and height of a Eucalyptus clonal settlement located in ETEC Prof. Dr. Antonio Eufrásio of Toledo. To evaluate the differences between treatments we used the procedure of analysis of variance and Scott Knott test at 1 and $5 \%$ probability. The results show that there is no difference between the treatments tested for the variable diameter at breast height and no difference for the variable height.
\end{abstract}

Keywords: Measurement, Comparison, Operators, Equipment, Eucalyptus 


\section{INTRODUÇÃO}

A mensuração florestal é a ciência que trata da determinação e/ou estimação das variáveis dendrométricas das árvores e povoamentos florestais, permitindo avaliar seu crescimento e determinar sua idade técnica de corte e produtos finais.

As duas variáveis mais utilizadas para a realização de levantamentos florestais são a altura total e o diâmetro a altura do peito (DAP), que é usado para o cálculo da área basal e do volume de madeira existentes em uma árvore ou floresta.

Para a confiabilidade de um levantamento florestal é necessário que se conheçam as suas fontes de erro, para assim tentar eliminar, ou ao menos minimizar o seu efeito sobre a precisão das medições. Segundo Soares et al. (2006), os erros ocorridos nas medições de diâmetro e altura de árvores são devidos a erros do operador (sistemáticos), problemas no instrumento (compensantes) e condições de observação.

Diante disso este trabalho testou a troca de operadores, equipamentos e condição de observação na medição das variáveis altura total e diâmetro a altura do peito para identificar à existência ou não de influência destas características durante a sua mensuração em um povoamento de Eucalyptus spp. localizado na ETEC Prof. Dr. Antonio Eufrásio de Toledo, em Presidente Prudente - SP.

\section{METODOLOGIA}

O presente trabalho foi realizado em um reflorestamento clonal do gênero Eucalyptus spp. da ETEC Prof. Dr. Antonio Eufrásio de Toledo, pertencente ao Centro Estadual de Educação Tecnológica Paula Souza (CEETEPS), localizado a Rod. Raposo Tavares, Km 561, município de Presidente Prudente/SP, cujas coordenadas geográficas são $22^{\circ} 10^{\prime} 32^{\prime \prime S}$ de latitude e $51^{\circ} 22^{\prime} 37^{\prime \prime O}$ de longitude.

Para a coleta da variável Diâmetro a altura do peito (DAP) foi utilizada uma fita métrica graduada e uma Suta Florestal de uso profissional em interação com 05 (cinco) operadores diferentes, resultando em 10 tratamentos. Foram mensuradas 5 linhas com 15 árvores em cada, totalizando 75 árvores por tratamento.

Para medição da variável altura total foram utilizados para coleta de dados os hipsômetros (2 tipos), clinômetro digital e o clinômetro 360ํem interação com 03 (três) operadores diferentes, posicionados em duas distâncias (12 e 20 m das árvores mensuradas), resultando em 12 tratamentos. Foram medidas 05 linhas com 10 árvores em cada, totalizando 50 árvores por tratamento. 
Cada linha foi considerada como sendo uma repetição e as árvores existentes em cada linha foram utilizadas para compor a média da repetição utilizada nas comparações.

Os valores obtidos pela aplicação dos diferentes tratamentos foram submetidos ao programa estatístico denominado ASSISTAT Versão 7.7 beta (Silva e Azevedo, 2002), onde foi utilizado o procedimento de análise de variância e Teste de Scott-knott a 1 e $5 \%$ de probabilidade para realizar a comparação entre os tratamentos.

\section{RESULTADOS}

As análises estatísticas para a variável Diâmetro a Altura do peito mostraram que não houve diferença significativa entre os tratamentos testados (Tabela 01 e 02).

Tabela 01. Quadro de Análise de Variância da análise de influência da troca de operadores e equipamentos na medição da variável Diâmetro a Altura do Peito (DAP).

\begin{tabular}{ccccc}
\hline FV & GL & SQ & QM & Fc \\
\hline Tratamentos & 9 & 197,89229 & 21,98803 & \multirow{2}{*}{$0,8143 n s$} \\
Resíduo & 40 & 1080,15725 & 2700393 & \\
\hline Total & 49 & 1278,04954 & & \\
\hline
\end{tabular}

** significativo ao nível de $1 \%$ de probabilidade $(\mathrm{p}<.01) ;{ }^{*}$ significativo ao nível de $5 \%$ de probabilidade $(.01=<p<$ .05); ns não significativo ( $p>=.05)$.

Tabela 02. Valores médios de Diâmetro a Altura do Peito nos diferentes tratamentos testados pelo Teste de Média de Scott-Knott.

\begin{tabular}{ccc}
\hline Tratamento & \multicolumn{2}{c}{ Média } \\
\hline 1 & 15,84546 & $\mathrm{~A}$ \\
2 & 15,55200 & $\mathrm{~A}$ \\
3 & 15,62902 & $\mathrm{~A}$ \\
4 & 15,60400 & $\mathrm{~A}$ \\
5 & 13,87746 & $\mathrm{~A}$ \\
6 & 21,78267 & $\mathrm{~A}$ \\
7 & 15,69480 & $\mathrm{~A}$ \\
8 & 15,22400 & $\mathrm{~A}$ \\
9 & 15,54583 & $\mathrm{~A}$ \\
10 & 15,52933 & $\mathrm{~A}$ \\
\hline $\mathrm{MG}=16,02846$ & $\mathrm{CV} \%=32,42$ & $\mathrm{DMS}=11,01557$ \\
\hline
\end{tabular}

Médias seguidas pela mesma letra não difere significativamente entre si pelo Teste de Tukey a 1 e $5 \%$ de probabilidade.

A análise de variância para variável Altura Total mostrou que houve diferença significativa a nível de $1 \%$ de probabilidade entre os tratamentos testados, pois, o $\mathrm{F}$ calculado foi maior que o $\mathrm{F}$ 
tabelado (Tabela 03).

Tabela 03. Quadro de Análise de Variância da análise de influência da troca de operadores, equipamentos e distancias na medição da variável Altura Total.

\begin{tabular}{ccccc}
\hline FV & GL & SQ & QM & F \\
\hline Tratamentos & 11 & 179,97244 & 12,36113 & \multirow{2}{*}{$6,2566^{* *}$} \\
Resíduo & 48 & 125,52154 & 2,61503 & \\
\hline Total & 59 & 305,49398 & & \\
\hline
\end{tabular}

** significativo ao nível de $1 \%$ de probabilidade $(p<.01) ;{ }^{*}$ significativo ao nível de $5 \%$ de probabilidade $(.01=<p<$ $.05)$; ns não significativo ( $p>=.05$ )

Segundo o Teste de Média de Scott - Knott a nível de 5\% de probabilidade, os tratamentos que diferiram dos demais foram os Tratamento 5, 6 e 8; ambos realizados pelo operador 2. A utilização de clinômetro 360ำ resultou em medidas iguais, demonstrando que houve um padrão na medição. Entretanto, houve diferença entre os operadores. Quando o operador 2 utilizou o clinômetro digital suas medidas divergiram, inclusive superestimando as medidas ao se distanciar mais da árvore, quando comparado com os outros operadores (Tabela 04).

Tabela 04. Valores médios das Alturas Totais nos diferentes tratamentos testados.

\begin{tabular}{cccc}
\hline Tratamento & Média & \\
\hline 1 & 17,46200 & $\mathrm{C}$ \\
2 & 17,23400 & $\mathrm{C}$ \\
3 & 16,98440 & $\mathrm{C}$ \\
4 & 18,34600 & $\mathrm{C}$ \\
5 & 19,46000 & $\mathrm{~B}$ & \\
6 & 20,64800 & $\mathrm{~B}$ & \\
7 & 16,82720 & & $\mathrm{C}$ \\
8 & 22,32000 & $\mathrm{~A}$ & \\
9 & 16,36400 & & $\mathrm{C}$ \\
10 & 16,95600 & $\mathrm{C}$ \\
11 & 16,90480 & $\mathrm{C}$ \\
12 & 17,96800 & $\mathrm{C}$ \\
\hline MG $=18,12287$ & $\mathrm{CV} \% 8,92$ & & \\
\hline
\end{tabular}

Médias seguidas pela mesma letra não difere significativamente entre si pelo Teste de Scott Knott a $5 \%$ de probabilidade. 


\section{DISCUSSÃO}

Os erros cometidos na medição do diâmetro são mais importantes que os cometidos na medição da altura, sendo que um erro de $1 \mathrm{~cm}$ na determinação do diâmetro corresponde a um máximo de 19\% no cálculo do volume; e um erro de $1 \mathrm{~m}$ na medição da altura, a apenas $14 \%$ deste mesmo volume (COUTO et al, 1989).

Freitas e Wichert (1998) ao comparar os instrumentos tradicionais de medição de diâmetro (suta florestal e fita métrica) e hipsômetros em interação com diferentes operadores também não observaram diferenças significativas, tanto para a população de eucalipto como para a população de pinus estudada por eles.

Diferente de Freitas e Wichert (1998) e semelhante a este trabalho em algumas variáveis testadas; Couto e Bastos (1988) citados por David (2011), concluíram que os fatores operadores, classes de altura, distância do operador em relação à árvore e instrumentos influenciam na magnitude do erro da estimativa das alturas. Couto e Bastos (1988) citados por DAVID (2011) avaliaram 05 hipsômetros (Blume Leiss, Haga, Suunto, Haglof (clinômetro digital) e Weise). Estes autores notaram ainda, que dependendo da classe de altura, os aparelhos apresentam erros diferentes; os quais aumentam à medida que o operador se afasta da distância ideal de medição da árvore (COUTO e BASTOS, 1988 aput DAVID, 2011).

Neste trabalho o operador 02 diferiu dos demais superestimando os valores da altura das árvores mensuradas, principalmente quando mais distante da árvore; corroborando com os resultados obtidos por Couto e Bastos (1988). Os resultados obtidos pelos operadores 01 e 03 vão de encontro àqueles observados por Freitas e Wichert (1998), o que faz acreditar que um bom treinamento dos operadores antes do manuseio dos hipsômetros pode evitar erros de determinação da variável altura total.

Embora não exista diferença entre operadores e equipamentos, sugerimos que não ocorra a troca de operadores dentro de uma mesma unidade amostral (parcela) de inventário florestal. Baseando-se nas coletas de dados, recomendamos o uso de ferramentas profissionais, por ser mais prático seu manuseio e por ter um princípio e material de construção de qualidade melhor.

A realização de treinamento prévio dos operadores e a escolha de equipamentos profissionais, cujo princípio de construção e precisão são melhores, mesmo que a princípio envolvam alto investimento, é recomendável para garantir dados mais confiáveis na mensuração de povoamentos florestais. 


\section{CONCLUSÕES}

Para a mensuração da variável diâmetro a altura do peito não houve diferença entre os operadores e equipamentos, desde que o operador se atente para as regras de medição, principalmente a altura de medição desta variável, que é de $1,30 \mathrm{~m}$ do solo. Medidas abaixo e acima de $1,30 \mathrm{~m}$ podem superestimar e subestimar os valores, respectivamente.

Embora a medição da variável altura total tenha apresentado diferença, concluiu-se que esse resultado não foi consequência dos diferentes equipamentos testados, mas ocorreu em função da falta de habilidade do operador; visto que os operadores 1 e 3 realizaram as mesmas medidas para ambos os equipamentos nas diferentes distâncias.

\section{REFERENCIAS}

COUTO, H.T.Z.; BATISTA, J.L.F.; RODRIGUES, L.C.E. "Mensuração e gerenciamento de pequenas florestas". Documentos florestais, n. 5, p. 1-37, 1989.

DAVID, H. Camil. Métodos de medição de altura de árvores em uma floresta nativa do sul do Espirito Santo. Monografia apresentada ao Departamento de Engenharia Florestal da Universidade Federal do Espirito Santo. Jerônimo Monteiro - ES: 2011.

FREITAS, A. G. de; e WICHERT, M. C. P. Comparação entre instrumentos tradicionais de medição de diâmetro e altura com o criterion 400. Piracicaba: INSTITUTO DE PESQUISAS E ESTUDOS FLORESTAIS, 1998. 7p.

SILVA, F. de A. S. e AZEVEDO, C. A. V. de. Versão do programa computacional Assistat para o sistema operacional Windows. Revista Brasileira de Produtos Agroindustriais, Campina Grande, v. 4, n. 1, p.71-78, 2002. http://dx.doi.org/10.15871/1517-8595/rbpa.v4n1p71-78

SOARES, C. P. B., NETO, FRANCISCO de P. e SOUZA, A. L. de. Dendrometria e Inventário Florestal. Viçosa: Ed. UFV, 2006. 276p.:il. 